\title{
Children's interdependent mobility: compositions, collaborations and compromises
}

Dr Bjorn Nansen (corresponding author)

Department of Computing and Information Systems, the University of Melbourne, Melbourne, Australia

9.23 Doug Mcdonell Building, the University of Melbourne, Parkville, Victoria, Australia, 3010. T: +613 8344 1447, E: nansenb@ unimelb.edu.au.

\section{Dr Lisa Gibbs}

Jack Brockhoff Child Health and Wellbeing Program, McCaughey VicHealth Centre for Community Wellbeing, University of Melbourne, Melbourne, Australia

T: 8344 0920, E: lgibbs@unimelb.edu.au

\section{Associate Professor Colin MacDougall}

Southgate Institute for Health, Society and Equity, and Discipline of Public Health, School of Medicine, Flinders University, Adelaide, Australia and Jack Brockhoff Child Health and Wellbeing Program, The McCaughey VicHealth Centre for Community Wellbeing, University of Melbourne, Melbourne, Australia

T: 7221 8412, E: colin.macdougall@ flinders.edu.au

\section{Associate Professor Frank Vetere}

Department of Computing and Information Systems, the University of Melbourne, Melbourne, Australia

T: 8344 1496, E: f.vetere@ unimelb.edu.au

\section{Dr Nicola Ross}

Glasgow School of Social Work, University of Strathclyde, Glasgow, Scotland

E: nicola.ross@gmail.com

\section{Dr John McKendrick}

Glasgow School for Business and Society, Glasgow Caledonian University, Glasgow, Scotland T: 0141331 8221, E: j.mckendrick@gcu.ac.uk 
This paper discusses findings from Australian research that used a qualitative and participatory methods approach to understand how children develop and negotiate their everyday mobility. Children's mobility negotiations are discussed in reference to interactions with parents, peers and places; journeys in relation to their multi-modality, compositionality and temporality; and mobility formations in terms of 'companionship'- travel companions, companion devices, and ambient companions. Children's mobility is characterised by interdependencies that both enable and configure this mobility. Three themes - compositions, collaborations and compromises - are used to detail and describe some of the ways these interdependencies take shape and unfold.

Keywords: independent mobility, children, mobility, mobile methods, companions, interdependency

\section{Introduction}

A significant research literature has developed in relation to children's independent mobility - defined as freedom to travel or move about neighbourhoods without adult supervision (Tranter and Whitelegg, 1994; Shaw et al. 2013). Following research identifying a dramatic decline in children's independent mobility between 1971 and 1990 (Hillman, Adams and Whitelegg, 1990), many studies have attempted to measure and account for the historical reduction of children's independent movement (e.g. O'Brien et al. 2000; Shaw et al. 2013; Tranter and Whitelegg, 1994; Zubrick et al. 2010).

Independent mobility is considered important for physical health, helping children to incorporate elements of active transport, such as walking and cycling, into their daily travel routines (e.g. Carver et al. 2008; Garrard, 2009; Thomson, 2009). Yet, mobility is also valued from a rights-based perspective for providing children with opportunities to access public space for play, recreation and citizenship (UNICEF, 1989). Broader approaches to child wellbeing, then, value independent mobility for fostering children's spatial, personal and social skills through navigating, interacting and connecting with physical and social environments (e.g. Malone, 2007; Ross, 2007; Skelton, 2009; Zubrick et al. 2010).

Research has examined forces delimiting children's everyday mobility, the dependencies, that shape or attenuate this movement. Many studies address external and regulatory factors, which include: changes to built environments and transportation policies (e.g. Carver et al. 2008; Whitzman et al. 2009); shifts in 
parental perceptions and rules (e.g. Prezza et al. 2005; Valentine and McKendrick, 1997; Zubrick et al. 2010); and changing cultural norms, values and lifestyles (e.g. Gill, 2007; Malone, 2007; Thomson, 2009).

Less is known, however, about ways children contribute to the process of establishing, maintaining, and negotiating their everyday mobility, especially in the Australian context.

In this paper we seek to add to the evidence by including children's perspectives on how they actively participate in negotiating and developing their everyday mobility. We critically engage the concept of independent mobility; describe our methods to understand everyday mobilities of children; and map the interdependencies of children's travel we found. We detail three themes of interdependency in children's everyday mobility - compositions, collaborations and compromises - and argue for a more child-centred and critical approach to understanding how child mobility is assembled, mediated and negotiated.

\section{Defining and developing concepts of independent mobility}

Independent mobility is understood as the freedom of children to move about without adult supervision (Tranter and Whitelegg, 1994; Shaw et al. 2013); from this definition the discourse around child mobility tends to be approached through dichotomies of active-passive or dependence-independence. Informed by this key concept, then, literature on children's mobility has tended to examine either whether children's travel involves physical activity, or the presence of a supervising adult.

Whilst independent mobility has illuminated our understanding of forces reducing children's movement in public space, critics have recently pointed to its uncritical acceptance of theoretical assumptions about independence (Mikkelsen and Christensen, 2009). Mikkelsen and Christensen (2009) argue that the concept of independent mobility privileges individual agency and autonomous modes of movement over shared or collective modes, and uncritically assumes a linear progression from supervised to unsupervised child mobility.

The concept of independent mobility encompasses both solitary child travel and travel accompanied by other children (Shaw et al. 2013), yet the emphasis on child-adult relations reduces the foci of much research to the physical presence or absence of an adult. Mikkelsen and Christensen $(2009,41)$ argue that 'a sole focus on constituting children's mobility in relation to adults makes what children do together 
invisible'. That is, an adult-centred approach elides other diverse relations or actors mediating and configuring children's mobility - and in particular the finding that for children, mobility is a thoroughly social experience characterised by the pervasive companionship of others - siblings, peers and pets (Mikkelsen and Christensen, 2009).

Focusing on child-parent relations or the barriers to child movement disregards diverse relations that constitute and characterise children's everyday mobility. There are some exceptions, showing how children acquire mobility (Kullman 2010; Ross 2007; Milne 2009), and how children perceive and negotiate local travel (Hume at al. 2005; Pain et al. 2005). Consequently, there have been calls to work more closely with children, to include their voices and experiences in research on mobility (Mikkelsen and Christensen, 2009; Shaw et al. 2013; Zubrick et al. 2010). Our research sought to shift the emphasis from forces imposed upon children by enquiring into the ways children actively participate in the process of negotiating their everyday mobility. This approach recognises children possess agency (e.g. James et al. 1998), but that such agency is produced and distributed through relational arrangements (Lee, 2005; Prout, 2005).

We describe these entangled relations through the concept of children's interdependent mobility, which accounts for ways child mobility is enabled and configured through a diversity of relations and materials. Our research contributes to evidence revealing how patterns and practices of children's everyday mobility are not simply determined by larger external forces, such as social, physical and policy environments. Instead, they also include children's own agency, their mobility companions, the affordances of technologies, and the mediated or peripheral presence of adults. Mobility is neither a dependentindependent nor an active-passive dichotomy. Rather than viewed in oppositional terms, dependence and independence should be conceived as part of a continuum of interdependence (Kullman, 2010; Mikkelsen and Christensen, 2009).

In between the poles of dependence and independence, there are many instances in which children are neither directly accompanied, nor wholly unaccompanied, by an adult. As children move about in public spaces they move in and out of places that are more or less populated by others, they move in shifting group compositions, their progress is mediated by people and technology, and their journeys are comprised of 
many modes of mobility. Our research explored the dynamics of these interdependencies by shifting focus from factors that attenuate or direct mobility such as parental decision-making and control to consider children's active role in negotiating their everyday mobility.

\section{Research design and methods}

The paper analyses data from a multi-method qualitative study conducted in the local government area (LGA) of Moreland in Melbourne, Australia during 2011 and 2012. This inner-suburban location was selected based on convenience in relation to a range of areal infrastructure characteristics that support mobility and existing research connections with the local primary schools. Whilst many findings may be limited by the urban and geographical specificities of the area, the study aimed to research the factors that enable children's mobility rather than the forces that limit it.

Moreland has a culturally and linguistically diverse (CALD) community, and is undergoing a process of gentrification. The southern parts of the LGA, in which this study was situated, have an extensive network of paths and public transport network, making it relatively easy to travel by foot or bicycle. The local government council has also published policies for improving health and mobility by acting on the built environment, including the Moreland Health and Wellbeing Plan and the Active Moreland Framework.

The methodology was based on a rights based, child-centred participatory approach (Alderson and Morrow 2004; Ennew et al. 2009) to understand how children negotiate and develop their everyday mobility in the contexts of parental rules, family routines, cultural influences, peer social connections, communication technologies, and neighbourhood environments. The methods began with site observation, moved to child focus group discussions, and then accompanying children on their travel journeys. This process was piloted with a class group of 8 primary school children in their final year of primary school who acted as research partners to help shape the research design. The methods were then repeated with different cohorts to compare across the transition from the last year of primary school (Year 6) to the first year of secondary school (Year 7); and although primarily oriented around children's perspectives, the methods were contextualised with parent and teacher interviews (see, Gibbs et al. 2012, for detailed methods 
description). The Year 6 - Year 7 cohort was selected because research shows the transition from primary to secondary school is an important stage in children's mobility development (Shaw et al. 2013).

We began by observing a number of key sites and routes within the research area over a four week period, initially touring the area by car and foot, and stationing ourselves outside schools, shopping centres, and recreational facilities at busy times of the day (before and after school). The aim was to gather contextual data on the physical and social environment and to familiarise ourselves with local children's patterns and practices of mobility, informing subsequent methods. We then undertook focus group discussions with children in groups of 5-8 $(\mathrm{n}=48)$, which were conducted in schools with groups of mixed gender and diverse cultural background, including African, Indian, Middle-Eastern and European descent. The discussions were centred on two visual photo-ordering exercises that used images depicting places of, and then objects involved in, their neighbourhood travel. Visual aids have been shown to be an inclusive technique for stimulating children's responses (Morrow, 2001), and we asked children to discuss and work together to order the importance of each image for their travel journeys.

We followed discussions with mobile methods. This involved travelling with ten children ( 6 boys, 4 girls) drawn from the focus groups on an everyday travel journey. Again, the cultural background of these children was diverse. Children took researchers on routine travel journeys, predominantly to and from the school but also to places such as shops and parks, to show how they normally travelled, with questions generated by the environments and interactions that were observed during the journey. Mobile methods have been used in child mobility studies, and by embedding research in movements and routes of travel, they have been shown to produce data unable to be captured in more discursive or static methods using surveys or focus groups (e.g. Kullman 2010; MacDougall et al. 2009; Ross, 2007; Ross et al. 2009). Our research methodology meant our sample was limited in size and scope to children who demonstrated a high-degree of freedom to travel unaccompanied by parents; and despite the culturally diversity of the participants is unable to compare demographic differences, such as gender or cultural background. Instead, the methods employed were designed to develop a more integrated understanding of how children's everyday mobility is negotiated, mediated and experienced. 
Employing a multi-method approach such as this has been shown to provide children with a range of opportunities to participate; to offer insights into children's perspectives and experiences; and to allow for cross-checking data and, thus, providing more robust findings (Darbyshire et al. 2005; Morrow, 2008). Qualitative data analysis occurred concurrently throughout the data collection process to explore, understand and conceptualise thematic issues in the formation and negotiation of children's mobility. The data for analysis consisted of the focus group discussion transcripts, and the researcher written notes arising from the observations of the travel journeys. These data sources were analysed separately initially using a thematic, inductive and iterative process, with the data coded into identifiable patterns, then organised into emergent themes (Green et al. 2007). The findings from the separate data sources were then combined to allow for comparing and contrasting the emerging themes and to develop a conceptual framework for understanding children's negotiations for independent mobility. This framework was then aligned with other relevant studies and existing theoretical frameworks to inform the development of a theoretical understanding of the data.

\section{Mapping the interdependencies of child mobility}

We argue that children's everyday mobility is defined by interdependencies - of relations and materials that help to constitute that mobility. The interdependencies of child mobility are negotiated through: transitions over time, technology mediation, travel companions, travel on particular routes, and by routines of family and social life. Rather than an activity that is either completely circumscribed, or alternatively an activity that can become completely autonomous or independent, child mobility patterns are assembled and mediated in ongoing ways.

To explain this assembly and mediation we generated a 'child mobility framework' (see table 1), which maps the spectrum of composition and control in child mobility that we observed in our research. The compositions of child mobility include groups of varying formality and scale and groups with varying degrees of adult presence (physical, mediated, absent); whilst distributions of control in these compositions 
include varying degrees of supervision, responsibility and surveillance between children and adults. We unpack the forms of mobility composition and control in the child mobility framework in relation to different travel modes using the example of school travel (see table 2). This table expands on table 1 by providing descriptions for each of the different active and inactive modes of travel children took to school, and then within these modes the different forms of adult presence and control that children experienced and negotiated. We suggest that this framework highlights the diverse interdependencies characterising child mobility, and serves as a resource for mapping the multiple actors assembling travel compositions and mediating control in children's travel.

We propose the mapping as a useful exercise in conceptualising and visualising this complexity so it can contribute both to the design of further research and to reshaping definitions and theories of children's mobility. The child mobility framework helps to represent the poles of movement forms in which compositions are either adult-led groups or lone-child situations. Whilst these poles dominate literature on children's independent mobility, the framework also shows a whole range of in-between child mobility compositions emerging from our research in which both the presence and the authority of adults are more ambiguous.

To explore the significance of such child mobility forms in which children are not simply accompanied and supervised by an adult, nor completely independent and autonomous, we explore children's everyday mobility through the theme of composition. Through this theme we identify a vocabulary for considering the various forms of 'companionship'- travel companions, companion devices, and ambient companions - that mediate and characterise children's mobility. These interdependent forms include children moving in groups with siblings, friends and pets, children carrying mobile phones or 'travel technologies' (Kullman, 2010), and children travelling along busier or populated routes, in places where - or at times when - other people are present.

Clearly the child mobility framework only provides a static snapshot of such travel compositions, and it is important to recognise that these interdependencies of child travel compositions are much more dynamic, shifting across categories over time and even journey. Moreover, the child mobility framework 
replaces a linear progression from dependence on to independence from adult with the recognition that change in relation to other people, events, routes, routines and so on helps to shape much more shifting arrangements of children's everyday mobilities. To draw attention to this dynamic quality to children's mobility development, the child mobility framework schematises varied distributions of control in the organisation of that mobility. In the analysis below we explore the developments and negotiations of control in child mobility through the themes of collaboration and compromise. Similar to mobility composition, child mobility collaboration and compromise involve a range of companions that operate to mediate, to ameliorate, or to extend the role played by adults in the travel practises of children.

Thus, from this framework we have developed three critical themes of children's everyday mobility which detail some of the dynamic and shifting relations presented in the more static table, and which we found in our research. These themes are: compositions, collaborations and compromises.

\section{Compositions}

Composition, defined as the act of combining parts or elements to form a whole, describes different companions and resources involved in the constitution of child mobility. In our study we examined the formations, arrangements and relations of children in the process of moving about. We found compositions of child mobility involved a number of travel 'companions': friends, phones and strangers.

Our observation research confirmed Mikkelsen and Christensen's (2009) findings that children's everyday mobility is characterised by the pervasive companionship of other people. Children typically travelled in groups with parents, siblings, and friends. In discussions with children, friends were described as common and preferred travel companions, as they provided company, support and conversation:

I take the train with Narelle'. We live near each other (Year 7, Female).

Friends give you confidence (Year 6, Male).

\footnotetext{
${ }^{1}$ Pseudonyms have been used to protect participant anonymity.
} 
If I got driven to school I wouldn't be able to catch the train with my friends and I would be really lonely in the car, with like no one to talk to. I don't like talking to my parents - they don't have anything good to talk about (Year 7, Female); ${ }^{2}$

They're so old (Year 7, Female);

I know, they talk about things like black and white TV, and I'm like, 'I don't care' (Year 7, Female).

When we spoke with children in groups and during mobile methods, we found their everyday mobility involved visible human companions, but also non-human companions: in particular companion devices such as mobile phones. Mobile phones emerged as a commonplace device in the everyday mobility of children in our study. Mobile phones were often handed-down from parents, specifically in relation to children's developing mobility, and as companion devices they served to mediate the presence of others at a distance:

My mum got a new iPhone, so she is giving me her old phone (Year 6, Male).

We will get him a mobile phone next year to be able to stay in touch (Parent, Male).

If you have like a new iPhone or something you could just go [to the] maps [App] and find your own way. Otherwise, you could just call your parents and say 'I'm stuck. I don't know where I am' (Year 6, Male).

I'm not allowed to leave the house without my phone, like 'just take your phone in case you get lost'. I'm not going to get lost! (Year 7, Female).

Thus mobile compositions involved physically present others, but also companionship that extends to the mediated or connected presence of others (Christensen, 2009). Finally, children spoke about the social and visible presence of other children and adults along the routes they travelled. These others were often strangers sharing public space so not playing a direct accompanying or supervisory role, yet their presence operated as a form of ambient companionship. This visibility creates a kind of casual or mutual surveillance (Ross, 2007), which is described as 'natural surveillance' in urban planning and crime prevention literature (e.g. Jacobs, 1962; Sutton et al. 2008). Significance was placed by children on travelling along busier routes

\footnotetext{
${ }^{2}$ Throughout the paper, in multi-sentence extracts, quotes separated with a semi-colon indicate a conversation
} 
and at popular times, in order to take advantage of the perceived safety benefits of social visibility and ambient companionship:

My mum gives me a route, like not to go down the side street (Year 6, Female).

'Cause there are a lot of people walking to the same area so maybe it's a bit safer (Year 6, Female).

It kind of feels more safe because you know there are adults around and the driver (Year 7, Male).

There's like this dodgy place near my house, it's kind of like an alley and they don't want me going through there (Year 7, Male).

Findings from this child-centred approach extend the observation that children's everyday mobility is a thoroughly social and mediated experience characterised by the pervasive companionship of others (Mikkelsen and Christensen, 2009). These different kinds of companions reveal that mobility compositions are assembled through both social and material arrangements, and such sociomaterial networks are comprised of actors in shifting relations of presence.

Whilst children's everyday mobility was mediated and constituted by varying relations of proximity and presence, group compositions did not remain static but often varied over the course of a travel journey. Children met friends or relatives along a route and accompanied them the rest of the way; or parents accompanied children for only part of a journey (e.g. to walk children to a main street). These multicompositional journeys meant that parts of a single journey - especially the school journey - were in groups, whilst others were unaccompanied:

I used to meet her half way or go to her house and then we'd walk together (Year 6, Female).

Mia is in grade 6 and her sister is in grade 4. She walks her with her sister...I used to walk with them to show them the way. They also meet their cousins on the way, who live near her, and they all walk together (Parent, Year 6 child).

involving different participants. 
In the afternoon I walk with my friend, we walk along Melville Road ${ }^{3}$ from school down here, and then he goes up there and I go down here (Year 6, Male).

The transition from primary to secondary school was important because school journeys were often further; resulting in multi-modal journeys comprised of different transportation modes. Symes describes this multimodality through the notion of 'choreographies' of movement, which are assembled through systems, infrastructures, vehicles, timetables and so on, meaning journeys are: 'rarely seamless [and]... likely to be discontinuous and multi-modal, involving walking, travelling on a bus and/or train, and periods of waiting' (2007: 450). Similarly, we found travel was not simply dependent or independent in relation to parents, nor solely active or passive in terms of physical activity:

Mum used to drop me off at Melville Road, and then I'd walk the rest of the way (Year 6, Female).

Most of the time I'll take a bus up to Sydney Road and then take a tram down to Dawson Street and then a bus up to the school; but it generally involves me running, like I have to sprint, to get to the bus (Year 7, Male).

I do notice when I'm doing duties outside that a lot of them find each other. So I'll have 3 or 4 in my class turn up together so they obviously walk the same route or pick each other up or get dropped at each other's houses and then come on from there (Teacher, Year 6).

\section{Collaborations}

Collaboration, the act of working together for a common purpose, describes how children's mobility is neither controlled by nor autonomous from others. Instead, children's mobility is assembled through the cooperation and assistance of a range of people, objects and environments, working in concert with children to enable them to move about in public. We found that collaboration occurred between children and parents, but also with and through friends, mobile devices and strangers:

3 Real street names have been used as those mentioned are popular tram routes and do not reveal participant home addresses. 
As noted, friends were common companions in children's everyday mobility, and their importance was referred to by both children and parents in terms of reassurance and safety:

At first I was kind of nervous but because I went with friends I was alright (Year 6, Female).

Friends make you feel more secure, if there's a stranger (Year 6, Female);

Friends give you confidence (Year 6, Female).

Next year our son will ride his bike with a group of children, we have friends who live in the street who already ride, so he will ride in a group, which is good (Parent, Year 6 child).

They (friends) might know the way around (Year 7, Male);

They can remind you to get off the tram (Year 7, Male);

They can alert you if you are about to go in front of a car (Year 7, Male).

Whilst there is general agreement on the important role played by friends for supporting children's mobility, the view in the literature of the role played by mobile phones is more equivocal. Mobile phones have been assessed in pejorative terms for their affordances - contactability and connectedness - enabling pervasive parental monitoring and thus inhibiting an ideal of independence. Fotel and Thomsen (2004), for example, argue that mobile phones can be viewed as a surveillance technology as they facilitate the parental 'remote control' of children's everyday mobility. For them, companion devices like phones remove the need for parents to be physically or co- present by making it possible to monitor children's mobility from a distance.

Mobile phones, however, can also be seen to mediate and enable greater confidence and independence. Pain et al. (2005) note, for example, the contactability provided by mobiles may help to: alleviate parental fears; free children and parents from set deadlines; expand children's spatial ranges and empower young people to reclaim public spaces. Nevertheless, whilst recognising that children gain a degree of empowerment by carrying a phone, the cost of this is often viewed as an 'invasion' of their space (Williams and Williams, 2005) - a sentiment that somehow mediated communication fosters an antagonistic rather than cooperative relationship. 
In our study, primary school aged children recognised an element of parental monitoring through mobile phones, particularly via texting their arrival at certain places or whereabouts at certain times, but largely viewed mobile phones as helpful for being able to contact their parents and thus offering security:

I text to let my parents know where I am (Year 6, Male).

When we leave our house 'cause our Mum's gone to work we have to say we've left and it's like 8.15 or something and then when we get to school we just say 'we're at school' (Year 6, Male).

Mine's just for emergencies (Year 6, Female);

I don't call my friends just my parents (Year 6, Female).

If you are in danger you can call someone (Year 6, Male).

Following the transition to secondary school students viewed phones as essential for their daily lives. Usage still included parental contact and safety measures; however they had developed a broader and more sophisticated use of their phones. These children saw phones as valuable in relation to re-scheduling or renegotiating meeting times/places with parents; and importantly saw mobile devices as entwined within their peer social relationships:

If your parents say to you be home at like 7 o'clock, you can call and tell them you'll be late (Year 7, Male).

We text each other to work out if we are going to meet on the second-last carriage or whatever, or if we are going to meet at McDonalds where the train stops (Year 7, Female).

Last year for my birthday we were going to the movies and we all got on the tram and we lost one person, she got on the wrong tram, and she called us and we said we were on the tram in front of her, so we had to wait for her (Year 7, Female).

Carrying a companion device to remain contactable provided a reciprocal sense of comfort and security, in which children felt safer knowing they were able to access their parents, and thus parents were not simply remotely monitoring their children but able to help support their children's developing mobility through a 
connected presence (Christensen, 2009). We suggest that a limited focus on the surveillance capacities of mobile phones needs to be viewed as part of a larger terrain of everyday and casual surveillance, which in practice works as part of an arrangement of collaboration rather than control.

This understanding of collaboration extends to the ambient companionship of others and the natural surveillance they provide. Busier or populated routes, places or times were felt as being more comfortable or safe than isolated or strange routes and places. For primary school children this typically involved taking, or not deviating, from a set route; whereas for secondary school children it was not so much a specific route that mattered, but rather ensuring they travelled routes that were more populated than others.

\section{Compromises}

Compromise, the settlement of differences by mutual concessions, highlights our finding that children's mobility is not granted or limited by a single authority, nor does it emerge through self-direction or actualisation. Instead it is shaped through more fluid and reciprocal negotiations over time as children actively seek out greater opportunities for mobility, and compromise their ambitions in relation to parental demands and the routines of family life. In turn, parents aim to support the development of their children's independence, and moderate concerns in relation to the developing capacities and negotiations of their children. These reciprocal arrangements involve further compromises through the social and material resources available to children - travel companions, companion devices, and ambient companions.

In one sense, we found that child mobility and 'independence' are progressively achieved over time. This progression or development in mobility occurred through stages whereby parents initially accompanied children to destinations, which shifted to allowing travel while 'shadowing' children, setting rules about routes to a destination, allowing independence if with friends or a mobile phone is carried, practicing new routes together, and finally allowing children to travel without parents present on public transport and to travel greater distances unaccompanied, with children deciding on their own route, companions, pace and so on:

Nerada is quite mature. And when we first started walking Nerada used to walk with a friend Bianca, so we'd drop her over at Bianca's house, and they'd walk together, and then when I was confident doing 
that we allowed them to walk to Melville Rd, and then we just added a bit every time (Parent, Year 6 child).

Our parents take us a couple of times and then we get used to it, so then we can go on our own (Year 6, Male).

At the start they will probably come with you and tell you all the roads and stuff but now I just say 'see ya' (Year 7, Female).

This transition from a more adult-led to child-led mobility (see table 1) can be conceptualised through a tether metaphor, where an initially tight tether is slowly untethered as children develop and display capacities for mobility. A visible example of this metaphor, from our observation research, occurred when primary school children left school, typically in groups - composed of parents, siblings, friends and pets. These groups were not tightly bound or orderly; but stretched out along the route as children walked or rode ahead without moving out of sight in a formation that suggested an early and partial untethering. Research has shown that children's feelings of moving through public space is mediated by encounters with adults, often unknown or official (Milne, 2009), yet the observation of untethering suggests such encounters are gradually made more familiar through initial experiences of place with the tether attached.

Nevertheless, the idea that such tethering is simply granted and directed by parents, or that transitions occur in a linear, progressive or structured way were challenged by the child and mobile methods research. Instead, we found that daily and weekly patterns of child travel varied in relation to a range of events and circumstances, such as weather, work, extra-curricular activities, public transport schedules and time of day:

If it's raining I get driven by my parents usually, but most of the time I'll take a bus (Year 7, Male).

It depends on whether my mum and dad are going to work. So sometimes I get driven by car and sometimes I ride my bike or scooter. Riding my bike is my favourite (Year 6, Male).

Children's everyday mobility was entangled with routines and schedules in ways that suggest the necessity to compromise ambitions challenges a normative or prescriptive ideal of progression towards independent 
travel.

Similarly, the idea that mobility is granted by parents or that rules are imposed and dutifully followed has been challenged by work in children's geographies (Valentine, 1997). Valentine explored the ways children challenged and redefined constructions of vulnerability by arguing for competence in their mobility negotiations with parents. The strategies to increase freedom Valentine noted were playing their parents off against each other, demonstrating prior experience or familiarity with a place, and failing this, children transgressing rules. Similarly, in our study children highlighted their negotiation tactics to travel places in their neighbourhood without supervision, such as: pleading, making a claim for maturity, ability or responsibility, nagging or selecting which parent to approach.

Alternatively, however, we found tactics also involved working with or through the compositions of mobility that parents promoted for safety - so children used the presence of companions, companion devices, and ambient companions as a tool to negotiate mobility with parents:

Sometimes I get my laptop and show them the route on Google whatever, so they know where I'll be going. Or I have my phone and say, 'just give me a ring' (Year 6, Male).

Maybe you say your friends are gonna be there or they're allowed to go (Year 6, Female).

Say you will go one way and won’t go down lanes (Year 6, Female).

For secondary school children, who were more circumspect about rules, transgression was viewed or used in some instances as a legitimate tactic. Rules imposed by parents were largely viewed as reasonable in relation to safety. In other instances they were viewed as unnecessary or overly restrictive and so efforts were made to challenge or circumvent rules in instances of lying or sneaking out:

Once I snuck out and went to my friend's house (Year 7, Female);

I snuck out. I know that's not responsibility or maturity, but they're so overprotective - you can't even go to a friend's house without them asking 'what time are you going to be back' (Year 7, Female).

Compromise and negotiation, however, was not just something that occurred within child-parent relationships. Instead, children recognised that the available social and material resources - travel 
companions, companion devices, and ambient companions - they collaborated with to support their everyday mobility could, in turn, compromise that very mobility.

As noted above, friends were often viewed by children as important for mediating their everyday mobility, providing companionship and a sense of safety (first two quotes, below). Yet, they also felt ambivalent about friends, noting the contradiction that friends also had a capacity to distract and endanger their travel (last two quotes, below):

If you have friends near you and you are lost your friend might know a path (Year 6, Male); And with your friends a stranger wouldn't come too close (Year 6, Female).

They can alert you if you are about to go in front of a car (Year 6, Male).

If you are talking with your friends you are more focused on walking and not on walking the way (Year 6, Female);

Sometimes friends can distract you (Year 6, Female);

Yeah like if they say 'hey listen to my music' (Year 6, Male).

They can pull jokes on you and tell you to get off at the wrong stop (Year 7, Male).

Similarly, mobile companion devices were seen by children to be important mobile collaborators for mediating presence and contactability, yet they too were acknowledged for distracting attention and potentially compromising travel plans or safety:

With a mobile you can tell your parents where you are (Year 6, Female);

Yeah but if you are texting while you are walking then boom! (Year 6, Male).

You stop (Year 6, Female);

But not everyone does (Year 6, Male);

Phones distract you (Year 6, Male);

Yeah but if you use them wisely they don't (Year 6, Female).

I was playing on my phone and I missed my stop (Year 7, Male).

Responsibility, then, was felt by children as something that accompanied their freedom. Freedom was characterised by children in terms of being able to determine their own pace or route, whilst responsibility 
was expressed through having to be observant, look after siblings, not lose money and so on:

You feel freedom. You can just get where you want. Just say your mum or dad is with you they say 'don't go so fast', but if I'm by myself I feel good (Year 6, Male);

It feels good, except sometimes I feel like I need them (parents) there at some points, because sometimes I see random people and they look like mysterious or sort of scary (Year 6, Female).

My parents trust me and I get the responsibility to do things independently, which is good (Year 7, Female);

Sometimes I take my little sister with me and it's really annoying (Year 7, Male);

Yeah I have two little sisters too and they're really annoying, I have to watch out for them (Year 7, Female).

\section{Conclusion}

In this paper we have argued that a more critical engagement with the conceptual underpinnings on children's mobility can lead to new understandings. By broadening the analysis of mobility, we found that children's everyday mobility is defined by interdependencies rather than a simple dichotomy between dependent-independent or active-passive. We also show how children's mobility patterns are assembled, mediated and negotiated in ongoing ways through what we have described as diverse compositions, collaborations and compromises.

Our analysis of the data from child centred methods shows child mobility compositions are assembled through varying socio-material arrangements in shifting relations of companionship - travel companions, companion devices, and ambient companions. These interdependent companions take shape and unfold through collaboration with, and the cooperation of, a range of people, objects and environments, working in concert with children themselves to enable them to move about and participate in public space. In turn, child mobility is subject to negotiation and compromise in relation to the interdependencies that give it shape.

Of critical importance is the finding that children possess a sophisticated understanding of their everyday mobility and its interdependencies. They are not passive subjects of rules and environments, but play an active role in assembling relational compositions of mobility. They recognise mobility companions 
are interrelated, and that they must negotiate these interrelations; they realise that collaborations of mobility entail liberties but also responsibilities; and ultimately they reveal ambivalence about the benefits and disadvantages of 'independent mobility'. They compromise their desire for independence with their enjoyment of parental accompaniment, and compromise their feelings of excitement and freedom with nervousness or fear.

These findings recognise children as agentive in assembling their everyday mobility, yet also that this agency emerges from and is mediated through interdependent relationships with different kinds of companions. This builds on the growing body of work within human geography exploring the practices, experience and materialities that constitute children's everyday mobilities (e.g. Barker et al. 2009; Skelton and Gough, 2013), which has emerged as part of the broader turn towards mobilities in social analysis (Urry, 2007). Mobilities research has detailed the ways that movement - whether of bodies, objects, capital, information or images - relies upon infrastructures and resources to support their flows; whilst the nascent mobilities research agenda within children's geographies recognises that children's movement is relationally organised through the ways they interact with and construct urban environments (Skelton and Gough, 2013).

The wider implications of our research, for both theory and practice, suggest that rather than focus on 'independence' in child mobility, it may be better to think about child mobilities as plural arrangements, and to identify and support the distributed agencies, networks of relations and interdependencies of movement that characterise children's everyday mobility. Our study was limited in size and scope to children who demonstrated a high-degree of freedom to travel to school, parks or shops unaccompanied by parents, and is unable to make gender or cross-cultural comparisons, yet this limitation speaks to factors that enable children's mobility rather than the forces that limit it. These factors highlight opportunities for communities, families and children to build capacities for mobility, and in turn perhaps points to a cultural shift in the historical decline of children's movement in public space.

\section{Acknowledgements}

This work was supported by the Victorian Health Promotion Foundation (VicHealth), under their Innovation grant scheme. School participation was supported through the Department of Education and Early 
Childhood Development. Authors Nansen, Gibbs and MacDougall also gratefully acknowledge support

from the Jack Brockhoff Foundation. The authors would like to express their appreciation to the children,

families, teachers and schools involved in this study for their generous contribution of time and experiences.

\section{References}

Alderson, P., and V. Morrow. 2004. Ethics, Social Research and Consulting with Children and Young People. Tanner's Lane: Barnardo's.

Barker, J., P. Kraftl, J. Horton, and F. Tucker. 2009. “The Road Less Travelled - New Directions in Children's and Young People's Mobility.” Mobilities 4(1): 1-10.

Carver, A., A. Timperio, and D. Crawford. 2008. "Neighbourhood Road Environments and Physical Activity Among Youth: The CLAN Study." Journal of Urban Health 85: 532-544.

Christensen, T. 2009. “'Connected Presence' in Distributed Family Life.” New Media \& Society 11(3): 433-451.

Darbyshire, P., C. MacDougall, and W. Schiller. 2005. "Multiple Methods in Qualitative Research with Children: More Insight or Just More?" Qualitative Research 5(4): 417-436.

Ennew, J., T. Abebe, and A.T. Kjørholt. 2009. The Right to be Properly Researched: How to Do Rights-based, Scientific Research with Children. Bangkok: Black on White Publications.

Fotel, T. and U. Thomsen. 2004. “The Surveillance of Children's Mobility.” Surveillance and Society 1(4): 535-554. Garrard, J. 2009. Active Transport: Children and Young People: An Overview of Recent Evidence. Melbourne:

Victorian Health Promotion Foundation.

Gibbs, L., C. MacDougall, B. Nansen, F. Vetere, N. Ross, I. Danic, I, and J. McKendrick. 2012. Stepping Out: Children Negotiating Independent Travel. VicHealth Report. Jack Brockhoff Child Health and Wellbeing Program, The McCaughey Centre, University of Melbourne.

Gill, T. 2007. No Fear: Growing Up in a Risk-Averse Society. London, Calouste Gulbenkian Foundation.

Green J., K. Willis, E. Hughes, R. Small, N. Welch, L. Gibbs, and J. Daly. 2007. "Generating Best Evidence from Qualitative Research: The Role of Data Analysis." Australian and New Zealand Journal of Public Health 31(6): 545-550.

Hillman, M., J. Adams, J. Whitelegg. 1990. One False Move, a Study of Children's Independent Mobility. London: Policy Studies Institute.

Hume, C., J. Salmon, and K. Ball. 2005. "Children's Perceptions of their Home and Neighborhood Environments, and their Association with Objectively Measured Physical Activity: A Qualitative and Quantitative Study." Health Education Research 20 (1): 1-13.

Jacobs, J. 1962. The Death and Life of Great American Cities. New York: Penguin Books.

James, A., C. Jenks, and A. Prout. 1998. Theorizing Childhood. Cambridge: Polity Press.

Kullman, K. 2010. "Transitional Geographies: Making Mobile Children.” Social and Cultural Geography 11 (8): 829846.

Lee, N. 2005. Childhood and Human Value: Development, Separation and Separability. Maidenhead: Open University Press. 
MacDougall, C., W. Schiller, and P. Darbyshire. 2009. "What are our Boundaries and where can we Play? Perspectives from Eight to Ten Year Old Australian Metropolitan and Rural Children.” Early Child Development and Care 179 (2): 189-204.

Malone, K. 2007. "The Bubble-Wrap Generation: Children Growing up in Walled Gardens.” Environmental Education Research 13(4): 513-527.

Mikkelsen, M.R. and P. Christensen. 2009. “Is Children's Mobility Really independent? A Study of Children's Mobility Combining Ethnography and GPS/Mobile Phone Technologies.” Mobilities 4 (1): 37-58.

Milne, S. 2009. "Moving Into and Through the Public World: Children's Perspectives on their Encounters with Adults." Mobilities 4 (1): 103-118.

Morrow, V. 2001. “Using Qualitative Methods to Elicit Young People's Perspectives on their Environments: Some Ideas for Community Health Initiatives." Health Education Research, Theory and Practice 16 (3): 255-68.

Morrow, V. 2008. "Ethical Dilemmas in Research with Children and Young People about their Social Environments." Children's Geographies 6 (1): 49-61.

O’Brien, M., D. Jones, D. Sloan, and M. Rustin. 2000. “Children's Independent Spatial Mobility in the Urban Public Realm." Childhood 7 (3): 257-277.

Pain, R., S. Grundy, S. Gill, E. Towner, G. Sparks, and K. Hughes. 2005. “'So Long as I take my Mobile': Mobile Phones, Urban Life and Geographies of Young People's Safety.” International Journal of Urban and Regional Studies 29: 814 - 830.

Prezza, M., F. Alparone, C. Cristallo, and S. Luigi. 2005. "Parental Perception of Social Risk and of Positive Potentiality of Outdoor Autonomy for Children: The Development of Two Instruments." Journal of Environmental Psychology 25: 437-453 .

Prout, A. 2005. The Future of Childhood. London: RoutledgeFalmer.

Ross, N. J. 2007. “'My Journey to School...': Foregrounding the Meaning of School Journeys and Children's Engagements and Interactions in their Everyday Localities." Children's Geographies 5 (4): 373-391.

Ross, N.J., E. Renold, S. Holland, and A. Hillman. 2009. "Moving Stories: Using Mobile Methods to Explore the Everyday Lives of Children in Public Care." Qualitative Research 9 (5): 605-23.

Shaw, B., B. Watson, B. Frauendienst, A. Redecker, T. Jones, with Hillman, M. 2013. Children's Independent Mobility: A Comparative Study in England and Germany (1971-2010). London: Policy Studies Institute.

Skelton, T. 2009. “Children's Geographies/Geographies of Children: Play, Work, Mobilities and Migration.” Geography Compass 3 (4): 1430-1448.

Skelton, T., and Gough, K.V. 2013.” Introduction: Young People's Im/Mobile Urban Geographies.” Urban Studies 50(3): 455-466.

Sutton, A., A. Cherney, and R. White. 2008. Crime Prevention: Principles, Perspectives, and Practices. Port Melbourne: Cambridge University Press.

Symes, C. 2007. "Coaching and Training: An Ethnography of Student Commuting on Sydney's Urban Trains." Mobilities 2 (3): 443-461.

Thomson, L. 2009. 'How Times have Changed': Active Transport Literature Review. Melbourne, VicHealth. 
Tranter, P., and J. Whitelegg. 1994. "Children's Travel Behaviours in Canberra: Car-dependent Lifestyles in a Low-density City." Journal of Transport Geography 2 (4): 265-273.

UNICEF [United Nations Children Fund] (1989) Convention on the Rights of the Child.

Urry, J. 2007. Mobilities. Cambridge: Polity.

Valentine, G. 1997. “'Oh Yes I Can' 'Oh No You Can't': Children and Parents' Understandings of Kids' Competence to Negotiate Public Space Safely.” Antipode 29 (1): 65-89

Valentine, G., and J. McKendrick. 1997. “Children's Outdoor Play: Exploring Parental Concerns about Children's Safety and the Changing Nature of Childhood." Geoforum 28 (2): 219-235.

Whitzman, C., M. Worthington, and D. Mizrachi. 2009. Walking the Walk: Can Child-Friendly Cities Promote Children's Independent Mobility? Melbourne: GAMUT [Australasian Centre for the Governance and Management of Urban Transportation].

Williams, S. and L. Williams. 2005. "Space Invaders: The Negotiation of Boundaries through the Mobile Phone.” The Sociological Review 53 (2): 314-331.

Zubrick, S.R., L. Wood, K. Villanueva, G. Wood, B. Giles-Corti, and H. Christian. 2010. Nothing but Fear Itself: Parental Fear as a Determinant of Child Physical Activity and Independent Mobility. Victorian Health Promotion Foundation (VicHealth), Melbourne.

\begin{tabular}{|c|c|c|}
\hline COMPOSITION & \multicolumn{2}{|c|}{ CONTROL } \\
\hline \multirow{2}{*}{ Adult-led group } & \multicolumn{2}{|c|}{$\begin{array}{l}\text { Institutional } \\
\text { Formally organised group; instituted and controlled by adults }\end{array}$} \\
\hline & \multicolumn{2}{|c|}{$\begin{array}{l}\text { Non-Institutional } \\
\text { Informal or routine arrangement; organised and controlled by adults }\end{array}$} \\
\hline \multirow{6}{*}{ Child-led group } & \multirow{3}{*}{$\begin{array}{c}\text { Adult } \\
\text { controlled }\end{array}$} & $\begin{array}{l}\text { Adult physically present } \\
\text { Subtle supervision of children, e.g. 'shadowing' }\end{array}$ \\
\hline & & $\begin{array}{l}\text { Adult presence mediated } \\
\text { Monitoring by adult from a distance using 'companion device' }\end{array}$ \\
\hline & & $\begin{array}{l}\text { Adult not present } \\
\text { Adult applies rules and instructions to child group }\end{array}$ \\
\hline & \multirow{3}{*}{$\begin{array}{c}\text { Child } \\
\text { controlled }\end{array}$} & $\begin{array}{l}\text { Adult physically present } \\
\text { Children organise and control journey }\end{array}$ \\
\hline & & $\begin{array}{l}\text { Adult presence mediated } \\
\text { Children can access adult using mobile 'companion device' }\end{array}$ \\
\hline & & $\begin{array}{l}\text { Adult not present } \\
\text { Children responsible for journey arrangements }\end{array}$ \\
\hline \multirow{3}{*}{ Lone child } & \multicolumn{2}{|c|}{$\begin{array}{l}\text { Natural surveillance } \\
\text { Lone child travels populated route in presence of 'ambient companions' }\end{array}$} \\
\hline & \multicolumn{2}{|c|}{$\begin{array}{l}\text { Remote surveillance } \\
\text { Lone child, but adult 'companion' present through mobile device }\end{array}$} \\
\hline & \multicolumn{2}{|c|}{$\begin{array}{l}\text { Limited surveillance } \\
\text { Lone child travels isolated route with less opportunity for surveillance }\end{array}$} \\
\hline
\end{tabular}

Table 1 - Child mobility framework 


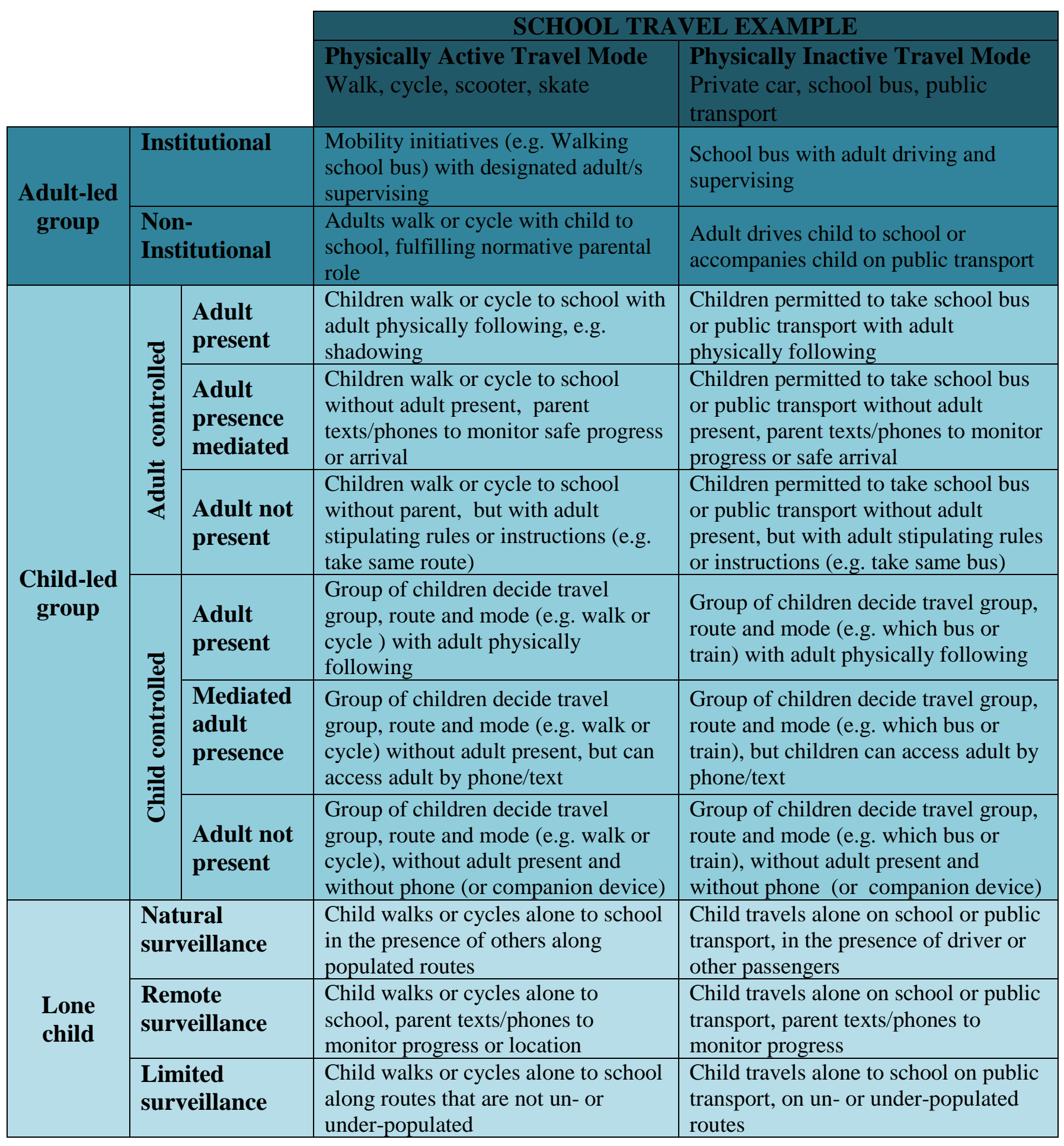

Table 2 - Example of child mobility framework for school travel 